УДК 330

ИНФОРМАЦИОННАЯ БЕЗОПАСНОСТЬ ЦИФРОВОЙ ЭКОНОМИКИ

Коваль Николай Вячеславович

студент

научный руководитель: Трифонов Юрий Васильевич

д.э.н., профессор

ННГУ им. Н.И. Лобачевского

«Институт экономики и предпринимательства»

\begin{abstract}
Аннотация: В современных условиях развития технологий, информационных и телекоммуникационных инфраструктур происходит формирование и увеличение новых угроз, связанных с защитой информации. Поэтому вопрос необходимости обеспечения информационной безопасности автоматизированных систем управления технологическими процессами, автоматизированных рабочих мест и критических информационных систем является крайне актуальным. Цель отразить значимость вопроса и основные аспекты защиты информационных систем, которые могут использоваться для компрометации критичных объектов информации. В данной статье рассмотрены основные направления, которые используют злоумышленники для проникновения в критические информационные инфраструктуры, способы защиты путем внедрения SOC.
\end{abstract}

Ключевые слова: информационная безопасность, цифровая экономика, компрометация банковских систем

\title{
INFORMATION SECURITY OF THE DIGITAL ECONOMY
}

\section{Koval Nikolay Vyacheslavovich Scientific adviser: Trifonov Yuri Vasilievich}

\begin{abstract}
In modern conditions of development of technologies, information and telecommunication infrastructures, the formation and increase of new threats associated with the protection of information is taking place. Therefore, the question of the need to ensure information security of automated control systems for technological processes, automated workstations and critical information systems is
\end{abstract}


extremely relevant. The purpose is to reflect the significance of the issue and the main aspects of the protection of information systems that can be used to compromise critical information objects. This article discusses the main areas that cybercriminals use to penetrate critical information infrastructures, methods of protection by implementing SOC.

Key words: information security, digital economy, compromise of banking systems

\section{Введение}

Все большую значимость в современном мире приобретает проблема информационной безопасности в условиях развития цифровой экономики. Изменения и трансформацию жизни людей можно заметить повсеместно.

Появляются новые профессии, рядовые сотрудники заменяются искусственным интеллектом (ИИ), использование наличных денег за последние пару лет уменьшилось на $70 \%$. Развитие данной отрасли происходит настолько стремительно, что обеспечивать безопасность электронных платежей, защищать объекты критической информационной инфраструктуры (КИИ) становится все сложнее. В основу цифровой экономики заложены большие данные.

По сути - это прогностическая экономика. Развитие происходит во всех направлениях и угрозы становятся все более серьезными, если раньше достаточно было набрать сотрудников в службу безопасности, которая физически защищала информацию, то сейчас основная защита должна приходиться на цифровой полигон, ведь основная угроза идет извне. Для того, чтобы заполучить деньги банка 40 лет назад достаточно было зайти в него и силой взять, что вам нужно.

Сейчас же достаточно иметь компьютер, доступ в глобальную сеть, навыки, а порой даже их не требуется. В данной статье рассматриваются основные проблемы информационной безопасности и способы защиты Компаний от несанкционированного доступа к ним.

Сегодня вызовы для информационной безопасности (ИБ) - это рост количества кибератак, дефицит кадров в сегменте ИБ, отсутствие отечественных аналогов программного обеспечения для защиты информации.

Данные угрозы вполне реальны, ведь ИБ - одна из составляющих национальной безопасности государства. 
В условиях цифровой экономики информационная безопасность имеет свою специфику.

Под угрозу попадают в первую очередь:

- Система статистики государства

- Системы бухучета организаций и предприятий

- Автоматизированные системы федеральных органов исполнительной власти

- Системы сбора, обработки, хранения и передачи информации

- Кредитно-финансовая система

Угрозы ИБ в условиях становления цифровой экономики:

- Компрометация информационных банковских систем

- Коммерческие организации (Угроза состоит в том, что деятельность этих структур в сфере создания и защиты систем сбора, обработки, хранения и передачи информации слабо контролируется и высока вероятность несанкционированного доступа к конфиденциальной экономической информации.)

- Хищение информации, содержащей коммерческую тайну (может нанести экономический ущерб предприятиям, вне зависимости от их формы собственности)

- Для обеспечения нормального функционирования экономической сферы необходима надежная защита от потенциальных угроз в информационном пространстве. Основные цели средств защиты информации - предотвращение и нейтрализация случайных и преднамеренных угроз ИБ.

Для обеспечения защиты стоит принять следующие меры:

- Разработать и внедрить системы электронных денег, платежей, а также платформы электронной торговли.

- Разработать средства защиты информации (СЗИ), а также внедрить эти средства в системы хранения, сбора и передачи экономической информации.

- Переподготовка сотрудников и обучение их работе со своими ПК с точки зрения информационной безопасности

- Разработка и внедрение системы мониторинга и реагирования на инциденты ИБ

- Участие в информационном обмене с ФинЦЕРТ и НКЦКИ

- Ограничение прав в компьютерных системах рядовых пользователей 
Отдельно хочется остановиться на существующих на данный момент способах и методиках защиты коммерческих и государственных организаций, а именно SOC (Security Operations Center).

B области защиты информации и способах реагирования на инциденты все большую популярность набирают Центры мониторинга информационной безопасности SOC.

SOC - это совокупность интегрированных друг с другом процессов, технологий и людей, объединенных для совместного противодействия злоумышленникам.

К основным функциям SOC можно отнести:

1. Мониторинг и реагирование на инциденты ИБ.

Обычно инженеры SOC собирают информацию (Логи) с рабочих мест сотрудников, сетевых устройств и других объектов компьютерной инфраструктуры в режиме 24/7, чтобы как можно раньше обнаружить и остановить возможную атаку.

В центрах SOC используют такие решения, как Security information and event management (SIEM) и Endpoint Detection \& Response (EDR).

2. Анализ подозрительной активности.

Получив уведомление об обнаруженном, инженер SOC расследует данный инцидент, определяет, есть ли угроза, и, если есть - каковы ее характер и степень опасности.

3. Реагирование на инциденты.

При обнаружении инцидента сотрудники SOC принимают меня по реагированию на инцидент: устранение м минимизация ущерба.

4. Восстановление инфраструктуры после инцидента.

Восстановление пострадавших систем, файлов и бэкапов и многое другое.

5. Расследование инцидентов.

Поиск причин и устранение изъянов в системах безопасности, предотвращение инцидентов в будущем.

6. Создание реестра защищаемых компаний.

Для успешной защиты и реагирования на инциденты, инженерам SOC необходимо знать, какие объекты входят в контур безопасности компании, какие ИБ-продукты используются и могут быть использованы для их защиты.

В России все большую популярность набирают коммерческие SOC, которые предоставляют свои услуги на аутсорсинге.

Преимущества аутсорсинга SOC: 


\section{1. Сотрудники}

Дефицит кадров на рынке IT - это существенная проблема. По оценкам Минкомсвязи РФ, прирост ІТ-специалистов за 2015-2016 годы составил всего 3,6\%. А потребность в таких специалистах, как посчитали в HeadHunter, растет на $25 \%$ ежегодно.

\section{2. Режим $24 / 7$}

На сегодняшний день обеспечение безопасности в формате 8/5 становится недостаточно. Злоумышленники "работают" и ночью и могут находиться в любом из часовых поясов. Обычно атаки происходят, когда снижается деловая активность, 50\% приходится на вечер пятницы. А это значит, что защита IT-инфраструктуры нужна в формате 24/7.

3. Быстрый запуск и выстраивание процессов защиты

Развитие своего SOC и выстраивание процессов внутри него может занять годы, в случае же с аутсорсингом можно быстро внедрять, а также оперативно повышать общий уровень зрелости информационной безопасности компании за счет современных технологий и методологий.

Также стоит обратить внимание на существование Computer Emergency Response Team (CERT).

CERT - это группа реагирования на компьютерные инциденты, представляющая из себя группу экспертов, в список задач которой входит постоянный мониторинг информации о появлении угроз в сфере информационной безопасности (ИБ), их классификация и нейтрализация. Целью деятельности CERT является своевременное реагирование на возникновение новых угроз ИБ и информирование об этом интересующихся лиц (подписчиков бюллетеня CERT).

Сегодня, существует сообщество, в которое входит более 800 компаний. Компании участвуют в информационном обмене с ФинЦЕРТ. Участники информационного обмена сообщают о выявленных ими угрозах и совершенных на них атаках, ФинЦЕРТ дает рекомендации по противодействию этим рискам. Это помогает оперативно реагировать на возникающие угрозы в финансовой сфере, не допускать их распространения, минимизировать потери финансовых организаций и их клиентов.

Одной из важных задач внутреннего CERT компании, является выявление релевантных Indicator of Compromise (IOC). Получив рассылку, допустим от ФинЦЕРТ или другой организации инженеры CERT проверяют IOC на релевантность и ставят их на мониторинг. 


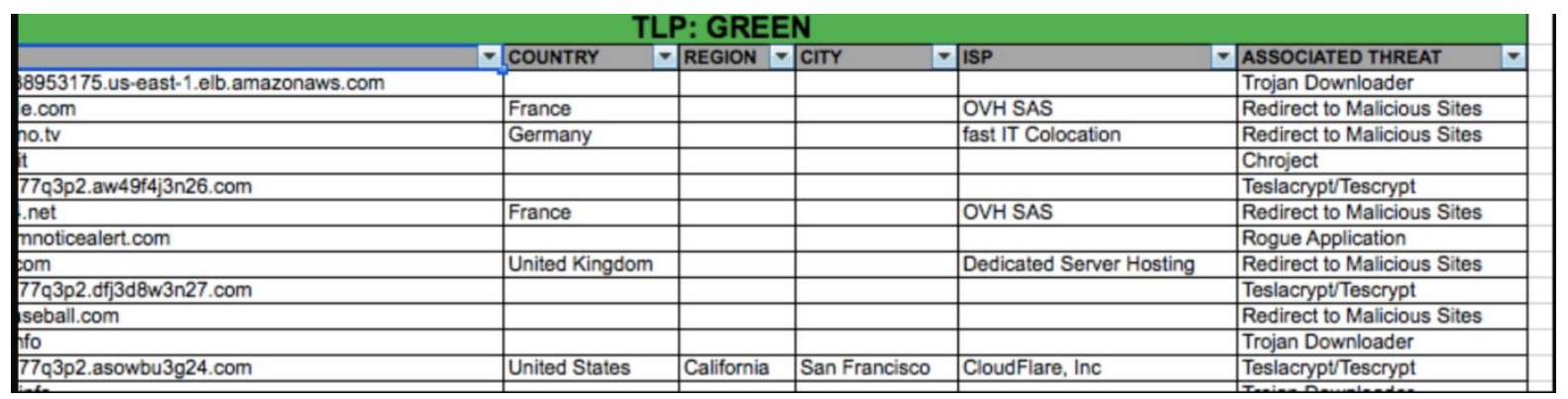

Пример: Список вредоносных доменов

Отдельно отметим, что даже обычный пользователь, который не относится к информационной безопасности может обезопасить себя, исследуя всемирную паутину. Например, использование открытых источников VirusTotal и AbuseIPDB.

VirusTotal - это pecyрс, который позволяет осуществить анализ подозрительных файлов, ссылок на предмет выявления вирусов, червей и многих других вредоносных программ.

AbuseIPDB - это проект, направленный на борьбу с хакерами, спамерами и другими злоумышленниками, которые занимаются вредоносной деятельностью.

Когда индикаторы компрометации поставлены на мониторинг при получении данного инцидента, обозначим его «Обнаружение индикатора компрометации Threat intelligence» инженер SOC может расследовать данный инцидент более глубоко, ведь индикаторы принадлежат АРТ-группировкам и имеют с ними связь. Существуют уже готовые сценарии, по которым инженер проводит расследование.

Пример оповещения:

\begin{tabular}{|c|c|}
\hline Заказчик: & ООО “Компания" \\
\hline $\begin{array}{l}\text { Время } \\
\text { сработки: }\end{array}$ & 20 SEP $202008: 02: 22$ \\
\hline Активность: & $\begin{array}{l}\text { Средствами Cisco ESA зафиксировано входящее письмо с адреса } \\
\text { post@сі[.]com, который является индикатором компрометации, на } \\
\text { адрес Компании сотаnу@сu[.]ru, по порту } 25 \text { (SMTP). } \\
\text { Тема письма: “Горящие туры в Анталию” } \\
\text { Отметим, что письмо содержит вложение “wannacry.exе” } \\
\text { Хеш-сумма: wdnui3223hd28392d9qw892389d892 } \\
\text { Показатель выявления вредоносов VirusTotal: 59/71 } \\
\text { Предположительно, данное вложение, является шифровальщиком } \\
\text { WannaCry. }\end{array}$ \\
\hline
\end{tabular}




\begin{tabular}{|c|c|}
\hline \multicolumn{2}{|c|}{ Продолжение Примера оповещения } \\
\hline $\begin{array}{l}\text { Информация } \\
\text { об источнике } \\
\text { активности: }\end{array}$ & $\begin{array}{l}\text {------Информация о системе------ } \\
\text { Индикатор: post@ci[.]com } \\
\text {------Информация о системе------ } \\
\text { Хост-источник: NB-ArefievaAN - 172.12.22.13 } \\
\text { Критичность хоста: } 7 \\
\text { Мас-адрес: 00-50-B6-5B-CB-6А. } \\
\text { Сетевая зона: asu_tp_zonelocation } \\
\text {------Информация о пользователе------ } \\
\text { УЗ: bt/ААN_corp } \\
\text { ФИО: Арефьева Алла Несторовна } \\
\text { Организация: ООО “Компания” } \\
\text { Департамент: Отдел обслуживания клиентов } \\
\text { Должность: Оператор саll-центра } \\
\text { Руководитель: Приметов Иван Иванович }\end{array}$ \\
\hline $\begin{array}{l}\text { Источник } \\
\text { событий: }\end{array}$ & Анализ активности с cisEsa - 120.221.12.32 (Cisco ESA) \\
\hline $\begin{array}{l}\text { Рекомендации } \\
\text { по } \\
\text { реагированию } \\
\text { на инцидент } \\
\text { ИБ: }\end{array}$ & $\begin{array}{l}\text { Отключить УЗ пользователя. Выключить компьютер и передать в } \\
\text { отдел компьютерной криминалистики для детального расследования } \\
\text { инцидента. Дать обратную связь. }\end{array}$ \\
\hline Примечание: & $\begin{array}{l}\text { WannaCry } \\
\text { Вредоносная программа, сетевой червь и программа-вымогатель } \\
\text { денежных средств, поражающая компьютеры под управлением } \\
\text { операционной системы Microsoft Windows }\end{array}$ \\
\hline
\end{tabular}

Получив данное оповещение, специалисты отдела ИБ заказчика могут оперативно отреагировать на инцидент и передать образ диска с зараженного ПК в CERT на анализ.

Подводя промежуточный итог, можем отметить, что наличие SOC в организации позволяет уменьшить время реагирования на инцидент и предотвратить дальнейшие инциденты.

Не редкость, когда незрелая с точки зрения ИБ компания подключается к $\mathrm{SOC}$ на аутсорсинге или заказывает услугу “тестирования на проникновение” и помимо огромного количества уязвимостей в системе, которые могут быть эксплуатированы, выявляются злоумышленники, которые уже давно находятся в инфраструктуре компании. 
Как следствие, если о данном инциденту придается огласка многие клиенты, которые заботятся о своей безопасности прекратят сотрудничество с данной организацией. Это влечет за собой как серьезные репутационные, так и финансовые убытки, а также может привести к банкротству компании.

Затрагивая сферу ИБ особенно в экономической области, можно привести множество примеров компрометации банковских систем, которые привели к серьезным последствиям.

Например, шифровальщик WannaCry за несколько дней приостановил деятельность многих организаций, речь пойдет не просто о кибератаке, а о выведении из строя целых корпораций.

Наиболее пострадавшими в данной кибератаке были Европа и Азия, среди пострадавших оказались крупнейшая телеком компания в Испании Telefonica, автоконцерн Reno, Germany Railway Station, Мегафон, Вымпелком, Сбербанк и МВД РФ.

Стоит отметить, что WannaCry причинил рекордный ущерб мировой экономике. Отметим, что злоумышленники суммарно в качестве выкупа получили всего 125 тыс. долларов, сумма не большая, но, если окунуться глубже в экономическую составляющую данной кибератаки и принять во внимание парализованные компании, которые подверглись воздействию данного ВПО, убытки сложно оценить. По самым скромным подсчётам убытки оцениваются в несколько десятков миллионов долларов.

Давайте разберемся, что такое шифровальщик и как он воздействует на ОС и распространяется в локальных сетях.

Основной принцип работы шифровальщика очень прост, он направлен на шифрование файлов и удаление копий файлов, таким образом, он делает невозможным восстановление так называемого бекапа файлов предыдущих версий. Как правило, шифруются файлы со стандартными расширениями, например, .exe .doc .xls и многие другие.

Теперь, когда вы понимаете, как работает шифровальщик, обратимся к нашему примеру.

Так все же, что такое WannaCry - это эксплойт, с помощью которого происходит заражение и распространение, плюс шифровальщик, который скачивается на компьютер после того, как заражение уже произошло.

Отметим, что WannaCry отличается от большинства шифровальщиков. Для того, чтобы заразить свой компьютер, обычным, скажем так, шифровальщиком, пользователь должен совершить некую ошибку - кликнуть на подозрительную ссылку, разрешить исполнять макрос в Word, скачать 
сомнительное вложение из письма. Заразиться WannaCry можно, вообще ничего не делая.

Данный вредонос является самостоятельной единицей, а именно достаточно одному человеку в локальной сети компании заразить свой ПК, например, заражение через электронную почту производилось только “Zero Users" далее вредонос самостоятельно распространялся по локальным сетям компаний.

В данном вирусе использовались самые современные стандарты ассиметричного шифрования, что исключало возможность лечения.

Мы отметили, что заразить свое АРМ можно, ничего не делая. Встает логичный вопрос, как такое возможно?

Давайте разбираться, если обычный шифровальщик нужно скачать и запустить, чтобы он начал свою работу то создатели WannaCry пошли другим путем. Создатели WannaCry использовали эксплойт для Windows, известный под названием EternalBlue или CVE-2017-0144- кодовое имя эксплойта, эксплуатирующего компьютерную уязвимость в Windows-реализации протокола SMB. После эксплуатации данной уязвимости злоумышленники получали удаленный доступ к компьютеру и устанавливали на него шифровальщик.

Как это работает?

Заранее подготавливается пакет и передается на удалённый хост, передав пакет на хост “А”, злоумышленник, способен получить удалённый доступ к системе и запустить на ней произвольный код.

После успешного запуска эксплойта через протокол $\mathrm{SMB}$, злоумышленники используют код ядра, чтобы внедрить себя в легитимный процесс lsass.exe, который всегда присутствует в системах Windows.

После успешного взлома компьютера WannaCry пытается распространяться по локальной сети на другие компьютеры, как червь. Он сканирует другие компьютеры на предмет наличия той самой уязвимости, которую можно эксплуатировать с помощью EternalBlue, и если находит, то атакует и шифрует и их тоже.

Получается, что, попав на один компьютер, WannaCry может заразить всю локальную сеть и зашифровать все компьютеры, в ней присутствующие. Именно поэтому серьезнее всего от WannaCry досталось крупным компаниям — чем больше компьютеров в сети, тем больше ущерб. 
Отметим, что единственный способ бороться с заражением - это не допускать заражения.

Компания Microsoft подтвердила, что уязвимости подвержены все версии Windows, начиная c Windows XР и заканчивая Windows Server 2016, то есть уязвимость оставалась неисправленной на протяжении, по крайней мере, 16 лет.

Уязвимость была устранена в серии обновлений MS17-010.

\section{Вывод}

Подводя итоги выше сказанного, хочется выделить несколько пунктов.

1. Своевременное внедрение СЗИ, настройка мониторинга и реагирования на инциденты ИБ, позволит сохранить репутацию и исключить финансовые издержки компании.

2. Обучения рядовых сотрудников взаимодействию с ИС с точки зрения ИБ ключевая задача любой компании, которая заботиться о своей безопасности и репутации.

3. Участие в информационном обмене с ФинЦЕРТ и НКЦКИ позволит получать актуальную информацию о существующих угрозах.

4. Ограничение доступа сотрудников в ИС исключит возможность компрометации системы изнутри компании.

5. Подбор технически грамотного управленческого состава с точки зрения ИБ исключит возможность откладывания в долгие критически важные действия.

\section{Список литературы}

1. Джейсон, А. Защита данных. От авторизации до аудита. - 2021 Режим доступа: https://book-pc.ru/bezopasnost/1149-zaschita-dannyh-ot-avtorizacii-doaudita.html

2. Джон, Э. Хакинг. Искусство эксплойта. - 2007 Режим доступа: https://book-pc.ru/programmirovanie/988-haking-iskusstvo-jeksplojta-2-e-izd.html

3. Виктор, О. Компьютерные сети. Принципы, технологии, протоколы: Юбилейное издание. - 2020 Режим доступа: https://book-pc.ru/setevyetekhnologii/71-kompjuternye-seti-principy-tehnologii-protokoly-jubilejnoeizdanie.html

(C) Н.В. Коваль, 2022 